\title{
The Obstetrics Gynecology and Children's Hospital Emergency Room waiting time before hospitalization
}

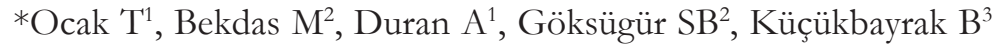

1. Abant Izzet Baysal University Faculty of Medicine, Department of Emergency Medicine, Bolu, Turkey

2. Abant Izzet Baysal University Faculty of Medicine, Department of Pediatrics, Bolu, Turkey

3. Bolu Izzet Baysal Government Hospital, Department of Pediatrics, Bolu, Turkey

\begin{abstract}
Background: One of the most substantial factors affecting patient satisfaction in the Obstetrics-Gynecology and Children's Hospital is the wait time in the emergency room.

Objective: We retrospectively studied the waiting periods of patients visiting the emergency room patients in Bolu Izzet Baysal Obstetrics-Gynecology and Children's hospital.

Method: Using an automated documentation system for each patient that recorded the season in which the patients consulted the emergency room, the month, day, time, examination time, hospitalization decision time, the hospitalization clinic following the decision to hospitalize, and the time to hospitalization, we retrospectively studied the waiting periods of emergency room patients in Bolu Ýzzet Baysal Obstetrics-Gynecology and Children's Hospital.

Results: A total of 15,004 patients who consulted the hospital emergency room between November 24, 2009, and August 25,2011 , and who were hospitalized in a clinic were included in this study. The highest frequency of emergency room patient visits occurred during the summer season (28.1\%), in the month of July (10.2\%), on Mondays (16.1\%), and between 8 and $11 \operatorname{AM}(22.1 \% ; p<0.05)$. The emergency room wait time of patients consulting the pediatric clinic was $(55 \pm 67 \mathrm{~min})$, which was significantly shorter than the wait time of patients consulting other clinics $(p<0.05)$.

Conclusion: The majority of patients who were hospitalized in any clinic through the emergency room consulted the hospital during the daytime hours. The time to hospitalization for the admitted patients was within an acceptable time frame. We believe that conducting comprehensive research to determine whether it is possible to reduce wait times even further to increase patient satisfaction will be instructive.

Key words: Emergency Room, acceptance-waiting time, emergency-waiting time, hospitalization-waiting time African Health Sciences 2013; 13(4): 1162 - 1169 http://dx.doi.org/10.4314/ahs.v13i4.43
\end{abstract}

\section{Introduction}

Any environmental or biological condition threatening human life and health is included in the realm of emergency services ${ }^{1}$. Emergency rooms are defined as health units that are obliged to provide uninterrupted 24-h emergency health services to patients presenting with an urgent situation ${ }^{2}$. The efficiency of emergency rooms is becoming increasingly important and has been addressed by legislation.

Prompt emergency room service is expected when patients present to an emergency room with urgent health problems. However,

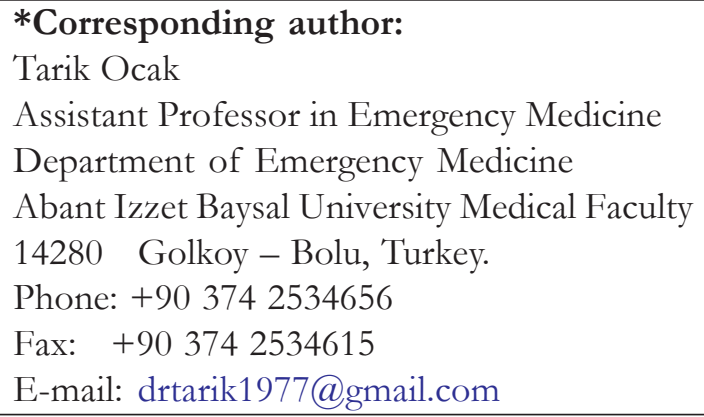

depending on various factors, the wait times for access to health services can be lengthy, and these factors can prevent timely intervention for patients consulting emergency rooms. As a result, the probability of serious problems such as disability and death has increased ${ }^{3,4}$.

Bolu Province, which covers $1.015 \%$ of the area of Turkey $\left(8,276 \mathrm{~km}^{2}\right)$, is located in the western Black Sea region. The majority of studies regarding emergency room wait times have been performed in complex emergency departments. However, to the best of our knowledge, no publications have provided detailed information regarding emergency room wait times for patients hospitalized in obstetrics-gynecology and pediatrics hospital clinics. Our study determined the emergency room wait times for patients who were subsequently admitted to the Obstetrics-Gynecology and Children's Hospital in the Bolu Province. 


\section{Methods}

Data from patients who consulted the emergency room at the Bolu Izzet Baysal ObstetricsGynecology and Children's Hospital and who were hospitalized between November 24, 2009, and August 25, 2011, were used in this study. Those who consulted the emergency room but were treated and discharged without hospitalization and those who left the hospital without waiting for examination were excluded from this study. The hospital's automated system provided chronological information on each patient in this study, including the season in which the patients consulted the emergency room, the month, day, time, examination time, hospitalization decision time, the hospitalization clinic selected following the decision to hospitalize, and the hospitalization time.

The acceptance waiting time was defined as the time between patient registration and patient examination by an emergency room physician. The emergency examination time was defined as the time period between patient examination by an emergency room physician and the hospitalization decision. The hospitalization waiting time was defined as the time from the decision regarding hospitalization to the actual hospitalization in a clinic. The data were evaluated using the Statistical Package for the Social Sciences (SPSS, Inc., Chicago, IL), version 17.0 for Windows. One-way ANOVA, the post hoc Tukey test, the independent-sample $t$-test, and the chisquared) test were used for statistical evaluation, and $p<0.05$ was considered statistically significant

\section{Results}

A total of 15004 patients who consulted the hospital emergency room between November 24, 2009, and August 25, 2011, and who were subsequently hospitalized in a clinic were included in the study. Of these, $446(2.9 \%)$ were pediatric surgery patients, $5672(37.8 \%)$ were pediatric patients, and 8886 (59.2\%) were obstetrics-gynecology patients.

The acceptance waiting time for patients consulting the emergency room in our hospital was 01 minimum and 101 maximum minutes, with a median value of 7 minutes. The emergency waiting time was 04 minimum and 390 maximum minutes, with a median value of 43 minutes. The hospitalization waiting time was 10 minumum 62 maximum minutes, with a median value of $10 \mathrm{~min}$.

Compared with the other days of the week, Mondays had the largest number of emergency room patients who were later admitted to the hospital, with a total of 2416 cases $(16.1 \%)$. The difference between patient density on Mondays and that on any other day was significant only for Sundays $(p<0.05$; figure 1).

Saturdays had the highest number of pediatric emergency room patients, with a total of 1090 cases $(19.2 \%)$. The number of patients admitted on Saturdays was significantly greater than that on Tuesdays, the day with the smallest number of patients $(p<0.05$; figure 1$)$.

The majority of patients who were hospitalized in the obstetrics-gynecology clinic consulted the emergency room on Mondays, with a total of $1567(17.6 \%)$ cases. The number of cases

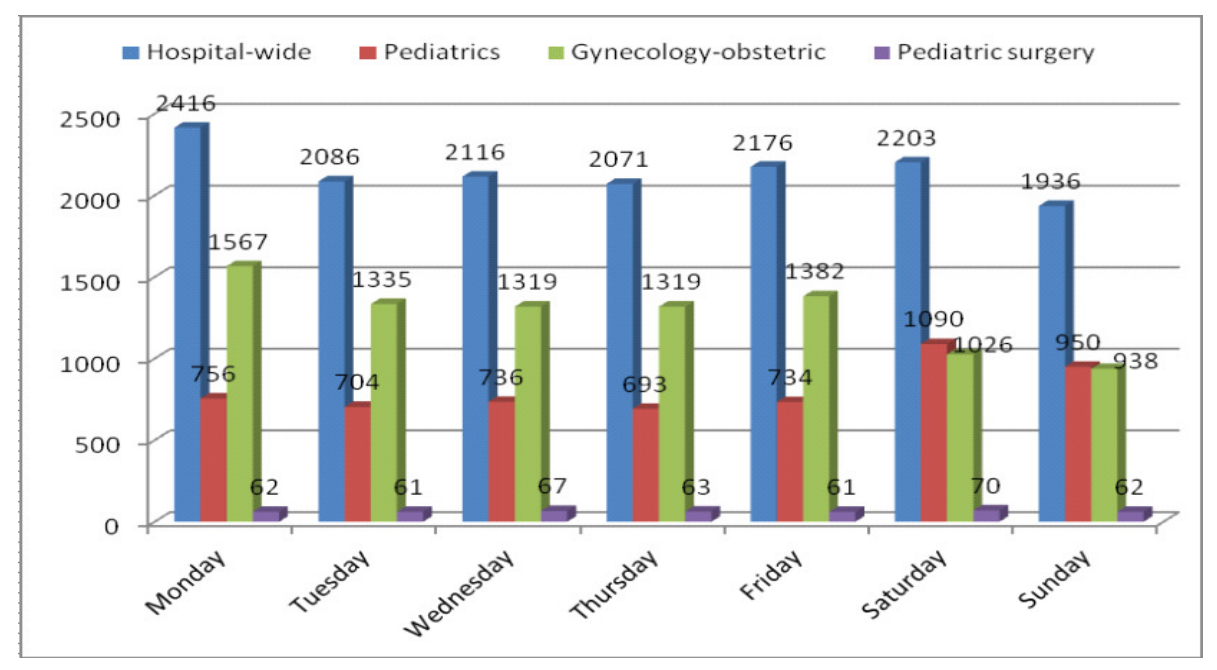

Figure 1: Patient distribution in pediatrics, pediatric surgery, obstetrics-gynecology, and the hospital in general according to days of the week 
admitted on Mondays was significantly higher than the number hospitalized on Sundays, the day with the smallest number of patients $(p<0.05$; figure 1$)$.

The majority of patients who were hospitalized in the pediatric surgery clinic consulted the emergency room on Saturdays, with a total of 70 cases $(15.7 \%$; figure 1$)$.

No significant difference according to day of the week was identified in acceptance waiting times, emergency waiting times, or hospitalization waiting times of patients consulting the emergency room in this study.

Emergency waiting times for patients consulting the obstetrics-gynecology emergency room were significantly shorter than those for patients consulting the pediatric emergency room $(\phi<0.05)$. No significant differences were identified among the other groups (table 1).

The number of patients who consulted the emergency room between $4 \mathrm{AM}$ and $7 \mathrm{AM}$ was significantly different from the number between 8 $\mathrm{AM}$ and $11 \mathrm{AM}(p<0.05$; table 2).

Acceptance waiting times was identified between patients presenting during the 12-3 AM, 4-7 AM, and 4-7 PM time frames and those who applied during the 4-7 AM and 8-11 PM time frames $(p<0.05)$. When the hospitalization waiting times were considered, a significant difference was identified only between those applying to the emergency room in the 12-3 AM and 12-3 PM time frames $(p<0.05$; table 2$)$.

When the 8-11am time frame (the time period with the highest frequency of emergency room visits) was compared with the other time frames, no differences were identified in the acceptance waiting times and emergency waiting times. However, the hospitalization waiting time in the 8-11am time frame was significantly longer than those for all other time frames except 12-3pm $(p<$ $0.05)$.

Although the emergency waiting times of patients consulting the obstetrics-gynecology emergency unit did not show a significant difference based on the application time, the acceptance waiting times and hospitalization waiting times were significantly different between 8-11am and 12-3am $(p<0.05)$.

With respect to seasons, 4214 cases $(28 \%)$ visited the emergency room during the summer, 4127 cases $(27.5 \%)$ during the spring, 3812 cases (25.4\%) during the winter, and 2851 cases $(19 \%)$ consulted the emergency room during the fall. A significant difference was identified when comparing the ratio of emergency room visits during the summer and fall seasons $(\phi<0.05$; table 3$)$.

Table 1: Distribution of the waiting periods in the emergency room depending on departments

\begin{tabular}{llll}
\hline Stand type & Service name & $\begin{array}{l}\text { Median } \\
\text { (minutes) }\end{array}$ & $\begin{array}{l}\text { Min-Max } \\
\text { (minutes) }\end{array}$ \\
\hline Accept-standby & Pediatric surgery & 8 & $3-613^{*}$ \\
& Pediatrics & 7 & $3-101^{*}$ \\
& Gynecology-obstetric & 7 & $1-101$ \\
& Total & 7 & $1-101$ \\
Emergency-standby & Pediatric surgery & 48 & $5-389^{\mathbf{a}}$ \\
& Pediatrics & 46 & $5-389^{\mathbf{a}, \mathbf{b}}$ \\
& Gynecology-obstetric & 41 & $4-390^{\mathbf{b}}$ \\
& Total & 43 & $4-389$ \\
Hospitalization-standby Pediatric surgery & 10 & $10-60^{\mathbf{d}}$ \\
& Pediatrics & 10 & $10-62^{\mathbf{d}}$ \\
& Gynecology-obstetric & 10 & $10-62$ \\
& Total & 10 & $10-62$ \\
\hline
\end{tabular}

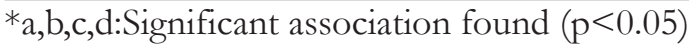


Table 2: Distribution of the patients in the pediatrics, pediatrics surgery, obstetric-gynecology and the hospital in general based on time frame

\begin{tabular}{|c|c|c|c|c|}
\hline \multirow[b]{2}{*}{ Stand type } & \multirow[b]{2}{*}{ Period } & \multicolumn{3}{|c|}{ Obstetric } \\
\hline & & $\begin{array}{l}\text { Median } \\
\text { (minumum; } \\
\text { maximum) } \\
\text { minutes }\end{array}$ & $\begin{array}{l}\text { Median } \\
\text { (minumum; } \\
\text { maximum) } \\
\text { minutes }\end{array}$ & $\begin{array}{l}\text { Median } \\
\text { (minumum; } \\
\text { maximum) } \\
\text { minutes }\end{array}$ \\
\hline \multirow[t]{6}{*}{ Accept-standby } & 00-03 am & $06(03 ; 95)^{*}$ & $06(03 ; 100)^{*}$ & $06(03 ; 100)^{*, \mathbf{d}}$ \\
\hline & 04-07 am & 07(03;99)* & $07(03 ; 95)^{*}$ & $07(03 ; 99)^{*, \mathbf{x}}$ \\
\hline & 08-11 am & $08(03 ; 96)$ & $07(03 ; 101)$ & $08(03 ; 101)^{\mathbf{d}}$ \\
\hline & $12-15 \mathrm{pm}$ & $08(03 ; 101)^{\mathbf{x}}$ & $08(03 ; 100)^{\mathbf{x}}$ & $08(03 ; 101)^{\mathbf{x}}$ \\
\hline & $16-19 \mathrm{pm}$ & $07(03 ; 101)^{\mathbf{x}}$ & $08(03 ; 100)^{\mathbf{x}}$ & $08(03 ; 101)^{*}$ \\
\hline & $20-23 \mathrm{pm}$ & 07(03;95) & $07(03 ; 99)$ & $07(03 ; 99)^{*}$ \\
\hline \multirow[t]{6}{*}{ Emergency-standby } & 00-03 am & $36(5 ; 382)^{\mathbf{a}}$ & $44(05 ; 386)^{\mathbf{a}}$ & $40(05 ; 386)^{\mathbf{a}}$ \\
\hline & 04-07 am & $43(05 ; 389)$ & $36(05 ; 386)^{\mathbf{a}}$ & $39(05 ; 389)^{\mathbf{a}}$ \\
\hline & 08-11 am & $58(05 ; 384)^{\mathbf{a}}$ & $43(04 ; 387)^{\mathbf{a}}$ & $47(04 ; 387)^{\mathbf{a}}$ \\
\hline & $12-15 \mathrm{pm}$ & $45(05 ; 374)^{\mathbf{b}}$ & $44(05 ; 372)$ & $45(05 ; 374)^{\mathbf{a}}$ \\
\hline & $16-19 \mathrm{pm}$ & $46(05 ; 387)^{\mathbf{b}}$ & $39(04 ; 388)$ & $41(04 ; 389)^{\mathbf{a}}$ \\
\hline & $20-23 \mathrm{pm}$ & $42(05 ; 389)$ & $37(05 ; 390)$ & $40(05 ; 390)$ \\
\hline \multirow{6}{*}{$\begin{array}{l}\text { Hospitalization- } \\
\text { standby }\end{array}$} & $00-03 \mathrm{pm}$ & $10(10 ; 58)^{\mathbf{c}}$ & $10(10 ; 62)^{\mathbf{b}}$ & $10(10 ; 62)^{\mathbf{c}}$ \\
\hline & 04-07 am & $10(10 ; 62)^{\mathbf{c}}$ & $10(10 ; 61)$ & $10(10 ; 62)$ \\
\hline & 08-11am & $10(10 ; 62)^{\mathbf{c}}$ & $10(10 ; 61)^{\mathbf{b}}$ & $10(10 ; 62)^{\mathbf{c}}$ \\
\hline & $12-15 \mathrm{pm}$ & $10(10 ; 60)$ & $10(10 ; 60)^{\mathbf{c}}$ & $10(10 ; 61)^{\mathbf{c}}$ \\
\hline & $16-19 \mathrm{pm}$ & $10(10 ; 62)$ & $10(10 ; 62)^{\mathbf{c}}$ & $10(10 ; 62)$ \\
\hline & $20-23 \mathrm{pm}$ & $10(10 ; 61)$ & $10(10 ; 62)^{\mathbf{c}}$ & $10(10 ; 62)$ \\
\hline
\end{tabular}

$*, \mathrm{x}, \mathrm{b}, \mathrm{b}, \mathrm{d}$ : Significant association found $(\mathrm{p}<0.05)$

Table 3: Distribution of the waiting periods in the emergency room based on season

\begin{tabular}{lll}
\hline Stand type & Season & $\begin{array}{l}\text { Median } \\
\text { (minumum;maximum) } \\
\text { minutes }\end{array}$ \\
\hline Accept-standby & Winter & $08(03 ; 99)^{*}$ \\
& Spring & $08(03 ; 101)^{*}$ \\
& Summer & $07(03 ; 101)^{*}$ \\
& Fall & $08(03 ; 101)$ \\
Emergency-standby & Winter & $47(05 ; 389)^{\mathbf{x}}$ \\
& Spring & $40(05 ; 390)^{\mathbf{x}}$ \\
& Summer & $43(04 ; 389)^{\mathbf{x}}$ \\
& Fall & $42(05 ; 382)$ \\
Hospitalization-standby & Winter & $10(10 ; 62)^{\mathbf{a}}$ \\
& Spring & $10(10 ; 62)^{\mathbf{a}}$ \\
& Summer & $10(10 ; 62)^{\mathbf{a}}$ \\
& Fall & $10(10 ; 62)$ \\
\hline
\end{tabular}

$*, x, \mathrm{a}:$ Significant association found $(\mathrm{p}<0.05)$ 
The average acceptance waiting, emergency waiting, and hospitalization waiting times of patients consulting the emergency room according to season are shown in table 4 . Acceptance waiting times during the spring season were significantly shorter than were those during the winter and summer seasons $(p<$ 0.05). Furthermore, the emergency waiting times during the spring season were significantly shorter than the acceptance waiting times during the winter and summer seasons $(p<0.05)$. The number of patients consulting the emergency room by month were identified between July and November, which were the busiest and slowest months, respectively $(\phi$ $<0.05$; table 4).

No significant difference in emergency waiting times and hospitalization waiting times was identified according to month. However, the acceptance waiting times during April and November were significantly different from those during June and September $(p<0.05)$.

Table 4: Distribution of the waiting periods in the emergency room based on months

\begin{tabular}{|c|c|c|c|}
\hline Months & Accept-standby time & $\begin{array}{l}\text { Emergency-standby } \\
\text { time }\end{array}$ & $\begin{array}{l}\text { Hospitalization-standby } \\
\text { time }\end{array}$ \\
\hline & $\begin{array}{l}\text { Median } \\
\text { (minumum;maximum) } \\
\text { minutes }\end{array}$ & $\begin{array}{l}\text { Median } \\
\text { (minumum;maximum) } \\
\text { minutes }\end{array}$ & $\begin{array}{l}\overline{\text { Median }} \\
\text { (minumum;maximum) } \\
\text { minutes }\end{array}$ \\
\hline January & $08(03 ; 93)$ & $45(04 ; 381)^{*}$ & $10(10 ; 62)$ \\
\hline February & $07(03 ; 95)$ & $45(05 ; 387)^{*}$ & $10(10 ; 62)$ \\
\hline March & $07(03 ; 101)$ & $37(05 ; 387)^{*}$ & $10(10 ; 62)$ \\
\hline April & $08(03 ; 95)^{*, \mathbf{b}}$ & $42(05 ; 390)^{*}$ & $10(10 ; 61)$ \\
\hline May & $08(03 ; 84)$ & $43(05 ; 389)^{*}$ & $10(10 ; 62)$ \\
\hline June & $07(03 ; 101)^{*, \mathbf{a}}$ & $37(05 ; 383)^{*}$ & $10(10 ; 62)^{*}$ \\
\hline July & $07(03 ; 97)$ & $50(05 ; 389)^{*}$ & $10(10 ; 61)$ \\
\hline August & $07(03 ; 96)$ & $44(05 ; 386)^{*}$ & $10(10 ; 62)$ \\
\hline September & $07(03 ; 100)^{\mathbf{b}, \mathbf{c}}$ & $40(05 ; 382)$ & $10(10 ; 62)$ \\
\hline October & $08(03 ; 99)$ & $44(05 ; 373)$ & $10(10 ; 62)$ \\
\hline November & $09(03 ; 101)^{\mathbf{a}, \mathbf{c}}$ & $47(05 ; 379)$ & $10(10 ; 61)$ \\
\hline December & $07(03 ; 99)$ & $54(04 ; 389)$ & $10(10 ; 61)$ \\
\hline
\end{tabular}

$*, a, b, c$ :Significant association found $(p<0.05)$

\section{Discussion}

Patients frequently visit emergency rooms without specific diagnoses. Patients with life-threatening conditions consult emergency rooms in Turkey and throughout the world; however it is difficult to prevent emergency room congestion and overcrowding because patients who do not require emergency care also consult emergency rooms $s^{5}$. It is particularly important that emergency room acceptance waiting times not interfere with the identification of life-threatening conditions and emergency intervention in critical patients; we believe that the most effective solution for this condition is an effective triage system.

Extreme patient density in hospital emergency rooms was first reported 20 years ggo $^{2}$. In recent years, long emergency room wait times and delay in commencement of treatment due to this waiting time are recognized as important problems in many countries ${ }^{2}$. The health system that has been modified and developed over the last 10 years in our country has improved patient access to health services. However, throughout Turkey, this improvement has resulted in patient accumulation and congestion in hospitals that was previously experienced only in emergency rooms of certain hospitals.

Emergency room congestion has increased over time and is dependent on the characteristics of the patients and seriousness of their conditions. Emergency room waiting and acceptance times have increased accordingly. Emergency rooms are not capable of controlling these characteristics, as they mainly reflect the social and economic characteristics of the environment in which hospitals are located. Wait times may be extended depending on whether the emergency room is the initial consultancy point, 
on the number of emergency room employees, on the physical status of the emergency room, and on the nature of the laboratory tests ${ }^{6,7}$.

Extended emergency room wait times result in a longer duration of pain experienced by patients, negative health effects, and reduced patient satisfaction ${ }^{8,9}$. Moreover, because of increased wait times, growing numbers of patients leave the emergency room without receiving medical care ${ }^{10}$. The recommended acceptable emergency room wait time for patients to gain access to an emergency room physician is $15 \mathrm{~min}^{11}$. However, the average wait time in US emergency departments was $38 \mathrm{~min}$ in 1997, and that time grew to $47.4 \mathrm{~min}$ in $2004^{12,13}$. According to various publications, the average emergency department wait times vary from $57 \mathrm{~min}^{14}$ to 92.5 $\mathrm{min}^{15}$. In a study conducted by Genç et al. ${ }^{16}$ in Turkey, the emergency room acceptance waiting time was $2.6 \pm 0.1 \mathrm{~min}$ (median, $2 \mathrm{~min}$ ), and the emergency waiting time was $77.3 \pm 3.6 \mathrm{~min}$ (median, $60 \mathrm{~min}$ ). In our study, the acceptance waiting time of patients consulting the emergency room was $11 \pm 13 \mathrm{~min}$, with a median of $7 \mathrm{~min}$. Although the recommended acceptable emergency waiting time is $15 \mathrm{~min}^{11}$, Banerjea et al. ${ }^{15}$ found delays of $377 \pm 261.3 \mathrm{~min}$. The emergency waiting time in our study was $62 \pm$ $64 \mathrm{~min}$, with a median value of $43 \mathrm{~min}$. The difference between the two results is related to the fact that no trauma patients consulted our hospital, which is an important factor in extending wait times.

The hospitalization waiting time in our hospital was $14 \pm 9 \mathrm{~min}$, with a median value of 10 min. These values may vary depending on a hospital's settlement plan, distance between units and the emergency room, the condition of the patient, patient density of the emergency room at a given time, and the status of the employees. Our data seem reasonable when considering these criteria related to our hospital and the time period required for preparing the patient's file for patient transfer after a making a hospitalization decision.

Parental decisions play a role regarding clinical and medical care received by children ${ }^{17}$, and this decision-making procedure also affects emergency room wait times. Bourgeois et al. ${ }^{18}$ reported that the pediatric emergency room patients' acceptance waiting time was $56.9 \mathrm{~min}$, and the emergency waiting time was 168.5 min. Banerjea et al. ${ }^{15}$ determined that the median length of pediatric emergency room patients' acceptance waiting time was $5 \mathrm{~min}$, and the median value of the emergency waiting time was $119 \mathrm{~min}$. In our study, the acceptance waiting time in the pediatrics department was $7 \pm 13 \mathrm{~min}$, and the emergency waiting time was $55 \pm 88 \mathrm{~min}$.

Banerjea et al. ${ }^{15}$ determined that the median acceptance waiting time for patients consulting the obstetrics-gynecology emergency room was 79 , $\mathrm{min}$ and the median emergency waiting time was $82 \mathrm{~min}$. In our study, the acceptance waiting time in the obstetrics-gynecology department was $7 \pm 12 \mathrm{~min}$, and the emergency waiting time was $54 \pm 91 \mathrm{~min}$.

The short waiting times observed in our study reflect the fact that trauma patients are not accepted to our hospital. The emergency waiting time for patients consulting the obstetrics-gynecology emergency room was significantly shorter than that for the patients in the pediatric emergency room in our study. This result may be due to the fact that our hospital is not an obstetrics and gynecology hospital, and the patients consulting the hospital for birth were able to gain rapid access to a physician.

Whereas some reports have indicated that a greater number of patients consult emergency rooms during the weekend ${ }^{19}$, other studies have detected no difference between the numbers of patients consulting emergency rooms during the weekend and that during the week ${ }^{20}$. In our study, the density of patients consulting the emergency room during the weekend was significantly different from that and during the week. Specifically, we showed that the density of patients consulting the pediatric emergency room was higher during the weekend, whereas the density of emergency room patients consulting the obstetrics and gynecology clinic was higher during the week. The number of the patients consulting the emergency room and the pediatric surgery clinic did not differ by days of the week.

With regard to the time frame of patient consultation to the emergency room, Booth et al. ${ }^{14}$ indicated that $28.6 \%$ of patients visited the emergency room between 5 and $9 \mathrm{pm}$, and $27.7 \%$ visited between $9 \mathrm{am}$ and $1 \mathrm{am}$. In our study, we showed that $22.1 \%$ of patients visited the emergency room between 8 and $11 \mathrm{am}$, and $21 \%$ visited between 4 and $7 \mathrm{pm}$. We believe the increased congestion in our hospital during the daytime hours is due to the shortage of physician specialists in our hospital; therefore, patients consult the emergency room for examinations. Xie et al. ${ }^{21}$ and Guttmann et al. ${ }^{22}$ indicated that patient congestion increased in the emergency rooms in the order $8 \mathrm{am}-4 \mathrm{pm}>4 \mathrm{pm}-$ $12 \mathrm{pm}>12 \mathrm{am}-8 \mathrm{am}$. These findings are congruent with those from our study. In contrast, Bourgeois et 
al. ${ }^{18}$ indicated that $50.5 \%$ of patients consulted the emergency room between $4 \mathrm{pm}$ and $12 \mathrm{pm}$. Booth et al. ${ }^{14}$ indicated that the average emergency waiting times were 53 min between $5 \mathrm{pm}$ and $9 \mathrm{pm}$ (the busiest time at the emergency service) and 56 min between 9am and $1 \mathrm{pm}$. In our study, the emergency room waiting time was $64 \pm 63 \mathrm{~min}$ between $8 \mathrm{am}$ and $11 \mathrm{am}$ and $62 \pm 66$ min between $4 \mathrm{pm}$ and $7 \mathrm{pm}$.

No difference was identified in the acceptance waiting times and emergency waiting times when the 8-1am time frame (the busiest time for patient applications to the hospital) was compared with other time frames. When compared with all other time frames excluding 12-3pm, the hospitalization waiting time in the 8-11am time frame was significantly longer than that at any other time. We believe that this problem was caused by the congestion encountered in all departments in the hospital during the 8-11am time frame, which slowed down the automation system in the hospital. Additionally, there may have been an insufficient number of employees in the hospital.

As expected, the waiting times increased with increasing numbers of patients in the emergency room, and the waiting times decreased with decreasing numbers of patients consulting the emergency room ${ }^{23}$. The waiting times increased in our emergency room between $8 \mathrm{am}$ and $11 \mathrm{am}$ when the density of the patients increased. The emergency room waiting times for patients admitted to the pediatric clinic were longer between $8 \mathrm{am}$ and $11 \mathrm{am}$ than during all other time frames, and the acceptance waiting times and emergency waiting times were significantly longer between 12 and $3 \mathrm{am}$. The emergency room acceptance waiting times and the hospitalization waiting times were significantly longer in the obstetrics and gynecology patients in the 8-11am and 12-3am time frames compared with the other time frames.

In Turkey, the numbers of patients who consult the emergency rooms are lowest during the spring and greatest during the summer, and the average number of patients differs depending on season ${ }^{19}$. Accordingly, Atherton et al. ${ }^{24}$ and Glass et al. ${ }^{25}$ indicated that the total number of emergency room patients increased during the summer season. Our study confirmed that the most applications were made during the summer and spring seasons. In contrast, Ye et al. ${ }^{26}$ indicated that the number of emergency room patients was greatest during the winter season. In contrast to the study conducted by Emet et al. ${ }^{19}$, we found that spring was the second most crowded season. This result might be due to increased allergic reactions in children during this season. The acceptance waiting period was significantly shorter during the summer (the busiest season) than during the winter season. This result might be related to the fact that a decreased number of extremely sick patients consulted the emergency room during the summer season.

Song et al. ${ }^{27}$ noted that the number of patients consulting emergency rooms increased from May to March. Battal et al. ${ }^{28}$ indicated that the period between November and February was the busiest time. Emet et al. ${ }^{19}$ identified the busiest month as July and the slowest month as March. In our study, we observed that the congestion, which began to increase in January, reached its maximum in July. We also found that November was the slowest month in the emergency room. In contrast, other studies have indicated that the emergency rooms are busiest from August to January ${ }^{21}$. Interestingly, we found that the acceptance waiting time during April to November was significantly longer than that during the period from June and September $(p<0.05)$.

\section{Conclusion}

The median value of the acceptance waiting times for patients consulting our emergency room was $7 \mathrm{~min}$, the median emergency waiting time was $43 \mathrm{~min}$, and the median hospitalization waiting time was $10 \mathrm{~min}$; these wait times are acceptable. The highest frequency of emergency room patient visits occurred during the summer season, in the month of July, on Mondays, and during the 8-11am time frame. The slowest times were observed in the fall, in the month of October, and during the 4-7pm time frame. We demonstrated that the acceptance waiting times, emergency waiting times, and the hospitalization waiting times were significantly longer during the periods with increased numbers of patients.

\section{References}

1. Kyriacou DN, Ricketts V, Dyne PL, McCollough MD, Talan DA. A5-Year Time Study Analysis of Emergency Department Patient Care Efficiency. Ann Emerg med. 1999;34(3):326-335

2. Weiss SJ, Derlet R, Arndahl J, et al. Estimating the Degree of Emergency Department Overcrowding in Academic Medical Centers: Results of the National Emergency Department Overcrowding Study (NEDOCS). Acad Emerg Med 2004; 11:3850

3. Derlet RW, Richards JR. Emergency Department Overcrowding in Florida, New York and Texas. South Med J 2002; 95:846-849.

4. Trzeciak S, Rivers EP. Emergency department overcrowding in the United States: an emerging 
threat to patient safety and public health. Emerg Med J 2003; 20:402-405

5. Bulut $H$. The effect of informaing patient and their relatives on satisfaction at emergency unit. Turkish Journal of Trauma and Emergency Surgery 2006; 12(4): 288-298

6. Varon J, et al. Ann Emerg Med 1994, 23: 546549) (Svenson J, et al. Am J Emerg Med 1997; 15: 654-657

7. Horwitz LI, Green J, Bradley EH. United States emergency department performance on wait time and length of visit. Ann Emerg Med. 2010;55(2): 133-141

8. Derlet RW, Richards JR. Overcrowding in the Nation's Emergency Departments: Complex Causes and Disturbing Effects. Annals of Emergency Medicine 1999; 35 (1): 63-8

9. Thompson, D. A., P. R. Yarnold, D. R. Williams, and S. L. Adams. Effects of Actual Waiting Time, Perceived Waiting Time, Information Delivery, and Expressive Quality on Patient Satisfaction in the Emergency Department. Annals of Emergency Medicine 1996; 28 (6): 657-65

10. Mc Namara KJ. Patient leaving the ED without being seen by physician:is same day follow-up indicated? Am J Emerg Med 1995;13(2):136-41

11. Clinical Initiative Centre: The clockwork, ed. Vol I, II and III. Washington DC:The Advisory Board, 1999

12. Nourjah P. 1999. "National Hospital Ambulatory Care Survey: 1997 Emergency Department Summary." Advance Data from Vital and Health Statistics; No. 304 [accessed on April 20, 2009]. Available at http://www.cdc.gov/nchs/data/ad/ ad304.pdf

13. McCaig, L. F., and E. W. Nawar. 2006. "National Hospital Ambulatory Care Survey: 2004 Emergency Department Summary." Advance Data from Vital and Health Statistics No. 372 [accessed on April 20, 2009]. Available at http:// www.cdc.gov/nchs/data/ad/ad372.pdf

14. Booth AJ, Harrison CJ, Gardener GJ, Gray AJ. Waiting times and patient satisfaction in the accident and emergency department. Archives of Emergency Medicine, 1992; 9: 162-168

15. Banerjea K, Carter AO. Waiting and interaction times for patients in a developing country accident and emergency department. Emerg Med J 2006;23:286-290

16. Genç M, Eðri M, Pehlivan E, et al. A study on waiting times of the patients applying on emergency department.J Inonu fac med 1999;6(4):337-9
17. Forrest CB, SimpsonL, Clancy C. Child Health Services Research: Challenges and Opportunities. J Amer Med Ass 1997; 277;(22): 1787-93

18. Bourgeois FT, Shannon MW. Emergency Care for Children in Pediatric and General Emergency Departments. Pediatric Emergency Care 2007;23(2):94-102

19. Emet M, Uzkeser M, Eroðlu M et al. The Rate of Annual Visits to the Emergency Clinic of a State Hospital and its Relationship with Time. EAJM 2007;39:119-123

20. Ceyhan MA. Factors affecting long wait times of patients in emergency department. (Thesis of specialization) Kayseri 2007 (http:// www.belgeler.com/blg/v1e/acil-servistehastalarin-uzun-bekleme-surelerine-etki-edenfaktorler-factors-affecting-long-wait-times-ofpatients-in-emergency-department)

21. Xie B, Youash S. The effects of publishing emergency department wait time on patient utilization patterns in a community with two emergency department sites: a retrospective, quasi-experiment design International Journal of Emergency Medicine 2011;4(29):2-7

22. Guttmann A, Schull MJ, Vermeulen M, Stukel TA. Association between waiting times and short term mortalityand hospital admission after departure from emergency department: population based cohort study from Ontario,Canada. BMJ 2011;342:d2983;1-8

23. Brun Romero FM, Benítez Macías JF, García Gil D, López Alvaro J. Changes in emergency admission times after the introduction of direct admission from emergency services. Rev Clin Esp. 2010; 4:159-62.

24. Atherton WG, Harper WM, Abrams KR. A year's trauma admissions and the effect of the weather. Int. J. Care Injured 2005; 36:40-6

25. Glass R, Friedman D. Trends in the demand for emergency room services: the Mount Sinai Hospital. Mount Sinai J Med 1977; 44: 560-5

26. Ye L, Zhou G, He X, Shen W, Gan J, Zhang M. Prolonged length of stay in the emergency department in high-acuity patients at a Chinese tertiary hospital. Emerg Med Australas. 2012 ;24:634-40.

27. Song H, Tucker AL, Murrel KL. The Impact of Pooling on Throughput Time in Discretionary Work Settings: An Empirical Investigation of Emergency Department Length of Stay. Harvard Busines School Working paper 2013; 13: 1-31

28. Batal H, Tench J, McMillan S, Adams J, Mehler PS. Predicting patient visits to an urgent care clinic using calendar variables. Acad Emerg Med. 2001; 8: $48-53$ 